

\title{
Sergio Vieira de Mello: El funcionario indispensable de Naciones Unidas
}

\author{
ANDRÉs Ramírez Silva
}

Coordinador general de la Comisión Mexicana de Ayuda a Refugiados, dependencia gubernamental encargada de conducir las políticas, estrategias y programas en materia de protección y asistencia a solicitantes de refugio, refugiados y extranjeros que reciben protección complementaria, en apego a la legislación nacional, acuerdos internacionales establecidos por el ejecutivo federal e instrumentos internacionales en la materia, para garantizar el respeto de los derechos humanos de esta población en México.

Es bien sabido que, por lo general, aquellos que sobresalen en cualesquier disciplina en la vida, comienzan desde temprano a zambullirse en sus aguas. Esa circunstancia, sin duda, potencia capacidades y dispara energías insospechadas que posibilitan a la persona, aún joven, acumular rápidamente una vasta experiencia. Claramente la inteligencia, la pasión por lo que hace, aspectos genéticos, el ambiente familiar, la educación, el contexto social y otros factores influyen, de modo significativo, en moldear al individuo no solo en cuanto a sus habilidades y potencial intelectual, sino en lo que atañe a sus principios y aspectos éticos. La conjunción de todo esos elementos peculiares definen la identidad de la persona, le confieren su carácter singular dentro de un contexto social particular inmerso, a su vez, en un universo global. Sergio Vieira de Mello, en tanto que funcionario de las Naciones Unidas, fue construido desde temprana edad. Caminó sus primeros pasos dentro de la organización a sus escasos veintiún años y desde entonces mostró precocidad inusual, variados talentos fuera de lo común y firme convicción. 
Vástago de diplomático, desde niño viajó mucho, aprendió otras lenguas y se alimentó de otras culturas. Estos antecedentes constituyeron un fogueo clave en el desarrollo ulterior de su carrera en la que tantas veces tendría que lidiar con las culturas más diversas y con las miradas más disímbolas. Su formación en filosofía y su participación en el movimiento estudiantil del 68 francés le nutrieron de la dosis de espíritu rebelde que ineluctablemente le templaron el carácter que tanto habría de necesitar en su futuro profesional.

$\mathrm{Su}$ puerta de entrada en las Naciones Unidas fue el ACNUR, agencia cuyo mandato se centra en la protección de los refugiados, en general, y más específicamente en la cooperación con los Estados signatarios de la Convención de 1951 y su protocolo de 1967 para garantizar la protección de los refugiados. Tal agencia le permitió beber desde muy joven del humanitarismo y el pragmatismo que habría de impregnarlo durante toda su carrera.

Dotado de una energía notable que vigorizaba su avidez por enrolarse en múltiples misiones con el ACNUR en períodos cortos, fue capaz de recorrer meteóricamente operaciones de la más diversa índole. Cuando comenzó con el ACNUR en 1969, apenas habían pasado dos años de la entrada en vigor del protocolo de refugiados del 67, aun vibraban las montañas y sabanas africanas por las guerras de descolonización cuando, por primera vez, una mujer africana, Angie Brooks, presidió la Asamblea General de las Naciones Unidas como expresión de la liberación del continente negro y del avance femenino. Ingresa Sergio (como sus colegas siempre le llamaban) al ACNUR el año de la Convención de la OUA, que marcaba un hito en la normativa jurídica regional para la protección de refugiados al ampliar la definición contenida en la Convención de Ginebra de 1951, Sergio fue instrumento personaje dentro del ACNUR en momentos históricos en que el epicentro de la Agencia de las Naciones Unidas para Refugiados acababa de trasladarse de Europa para África.

Desde sus inicios con el ACNUR empezó a trabajar en el terreno. Laboratorio insustituible donde pudo aplicar sus conocimientos teórico filosóficos a la realidad concreta. Seguimiento de las enseñanzas kantianas intentó realizar una síntesis entre el pensamiento racional y el empirismo, así dio sus primeros pasos en la Agencia para Refugiados bajando de la nube abstracta para situarse en la terrenalidad de la asistencia humanitaria, prestando ayuda a la distribución de alimentos en Bangladesh. Con esa actividad, comenzó a darse cuenta que su amor por la filosofía no era menor que su amor por la acción humanitaria y poco después, ese sentimiento se afianzó cuando fue invitado a participar de una operación en Sudán donde tuvo la oportunidad de asistir directamente del traslado aéreo de enseres domésticos y alimentos para refugiados que eran repatriados después de la firma del acuerdo de paz con los rebeldes del sur tras 17 años de guerra civil. 
Poco tiempo después, el joven brasileño a sus 33 años empezó a entender que en las Naciones Unidas, como en muchos otros empleos, también había espacio para la frustración. Fue en Líbano cuando tras alejarse temporalmente del ACNUR trabajó como asesor político del comandante de las fuerzas de Operación de Paz en el Líbano (UNIFIL), allí se dio cuenta de lo poco que la ONU podían hacer ante los rencores y discordias de las partes en conflicto, tanto que ante la impotencia llegó a sentirse avergonzado de ser funcionario de ese organismo. Aunque UNIFIL había sido establecida para monitorear la salida del ejercicio israelí al sur de Líbano, la verdad es que nuestro personaje pudo constatar en piel propia, la absoluta inoperancia de UNIFIL, mientras que los israelís apostaban a que su invasión originase la salida de la Operación de Paz.

Con la meteórica adquisición de notable experiencia, Vieira de Mello fue nombrado en el 83 adjunto de Kofi Annan, quien encabezaba el departamento de Recursos Humanos en el ACNUR, parecía entonces que se disponía a combinar una carrera de operaciones complejas en el terreno con cargos gerenciales a nivel de la sede. Sin embargo, su temple y constante inquietud por ubicarse rápidamente donde estaba la acción, acaba por empujarlo a nuevos cargos en los lugares más complicados. Su vocación innata lo llevaba ineludiblemente al terreno, fue allí donde potenció permanentemente sus cualidades más esenciales para el brillante desempeño de sus funciones.

La importante participación de Vieira en el manejo de la repatriación de 360,000 refugiados camboyanos de Vietnam marcó una huella indeleble en cómo debe conducirse una operación compleja en el ACNUR. Aún no se asentaba el polvo de la caída del muro de Berlín, la post guerra fría era un escenario en ciernes no dirigido todavía por nadie. Parecía que alumbraba un nuevo mundo unipolar de las entrañas del viejo mundo bipolar con miles de interrogantes.

La Unión Soviética acababa de desmembrarse. Apenas firmado el acuerdo de paz de Paris por las cuatro facciones Camboyanas en Octubre de 1991, el conjunto de seguridad autorizó el establecimiento de una misión de mantenimiento de paz llamada "Autoridad Transicional de las Naciones Unidas en Camboya" (UNTAC); Sergio fue entonces nombrado por la Alta Comisionada del ACNUR, Sadako Ogata, como enviado especial y, al mismo tiempo, le fue asignada la Coordinación del Pilar de la repatriación de la Autoridad Transicional de las Naciones Unidas en Camboya (UNTAC). La clave de su éxito fue la construcción de un equipo extremadamente competente a su alrededor. Esa fórmula no era fortuita, ni nacía de la ocasión. Fue en él, una constante que mostró su eficacia en reiteradas oportunidades. Me atrevo a agregar que no se trataba solo de organizar a un gran equipo, sino en saberlo dirigir, encauzar y motivar. De modo que las cualidades del carioca no se limitaban a identificar y seleccionar al 
equipo en las posiciones adecuadas, sino en mantener en ellos la llama viva de su pasión por lo que hacían. Los miembros y solistas de la orquesta eran virtuosos pero la batuta en manos del talentoso maestro era brillante, iluminadora y vibrante. La operación que le fue encomendada en Camboya, no era fácil. Más bien tenía una buena dosis de riesgo dado el alarmante número de minas antipersonales y UXOs sembrados en el país, lo que trágicamente se reflejaba en el enorme número de población amputada por causa de esas terribles armas invisibles. Contra la opinión de muchos que veían el elevado riesgo para la población repatriada, Sergio optó por la audacia. Mientras algunos le elogiaban su determinación y su seguridad, otros le criticaban su actitud apresurada y temeraria.

Los principistas de la protección consideraban que no se podía lanzar al azaroso terreno minado camboyano a la población civil inocente de modo imprudente, pero para Sergio no era el ACNUR quien debía decidir el destino de la población sino la propia gente. Para Sergio, la cuestión tenía que ver más con respetar y apoyar la decisión de la población que voluntariamente se quería repatriar más que imponerle el punto de vista de "los principistas" quienes, a su entender, se guarnecían bajo el escudo de "la protección" para disimular su paternalismo.

Camboya fue también un bautizo de fuego para el osado brasileño en lo que concierne a su decisión por negociar directamente con el Khmer Rojo, en tanto muchos de los refugiados inevitablemente se estarían repatriando a tierras ubicadas en territorio controlado por esa organización radical maoísta. Para Sergio, si la gente así lo decidía voluntariamente, el ACNUR apoyaría y asistiría la repatriación de camboyanos a tierras bajo el control del Khmer Rojo, para lo cual necesitaba garantías de que los expertos de la Naciones Unidas pudieran tener libre e irrestricto acceso a esos territorios con la finalidad de que pudieran evaluar la situación en materia de salud, agua y minas antipersonales.

Fue por esa necesidad imperiosa y por su convencimiento de que había que comprometer de manera constructiva al Khmer Rojo, que Sergio realizó la primera vista oficial de personal internacional de la ONU al territorio de esa organización por muchos temida. Para otro tipo de principistas, aquellos que se niegan a dialogar con grupos rebeldes $u$ organizaciones guerrilleras, al socaire de que con esas organizaciones no se puede confiar, Sergio parecía demasiado ingenuo. La verdad es que lo suyo era un pragmatismo necesario y resuelto para llevar a cabo las tareas que le habían encomendado.

Por otro lado, la experiencia en Camboya le reveló que su trabajo cada vez más lo empujaba hacia el terreno político, navegaba en los mares humanitarios para logar ver en el horizonte tierras políticas y se percataba que era en esas tierras donde se 
podían resolver los problemas y no en la esfera humanitaria donde, a lo sumo, conseguía paliativos al sufrimiento humano. Lo humanitario ni prevenía ni evitaba el desastre, era en el ámbito político donde podrían prevenirse los conflictos y era también ahí donde los mismos podían resolverse. Sergio había aprendido con destreza y gran habilidad como utilizar los derroteros humanitarios para tener un impacto político, pero sabía muy bien que ese mecanismo era limitado. Cada vez tenía más claro que los senderos políticos podrían ser una herramienta mucho más eficaz para logar dar respuesta a todo tipo de desafíos, incluidos los humanitarios.

Así, fue nombrado Consejero Político del Representante Especial del Secretario General en la Antigua Yugoslavia. En esa operación, Sergio tuvo que contrarrestar las fuertes críticas de quienes acusaban a UNPROFOR que fue establecida por el Consejo de Seguridad para escoltar a los trabajadores humanitarios con la intención de que pudieran dar asistencia a la población, que consistía en el levantamiento de un puente aéreo a Sarajevo sitiada por francotiradores serbios, Sergio rápidamente consiguió hacerse popular entre los oficiales de UNPROFOR con cuya mayoría podía hablar en su lengua materna.

A pesar de los ataques de los serbios, Sergio sostenía el punto de vista según el cual si UNPROFOR respondía a la agresión se podría poner en riesgo la operación humanitaria y la distribución de alimentos haciendo peligrar la vida de millones de personas. Para él, lo más importante era que se salvaban vidas, mientras que simultáneamente se compraba tiempo para avanzar en las negociaciones de paz. La clave, en su opinión, estaba en la imparcialidad como estrategia para detener la guerra, pero para Sergio era muy importante distinguir entre la lógica en tiempos de guerra y la lógica de mantenimiento de paz. La verdad, siguiendo a Kofi Annan en su libro Intervenciones, la onU fue llamada a participar en operaciones de mantenimiento de paz en medio de guerras brutales tanto en Ruanda como en Bosnia. Es decir, en países donde no había en realidad ninguna paz que mantener. 
Sin embargo, la tenacidad y habilidad de nuestro personaje rindió algunos frutos importantes, en lo referente a aliviar un poco el terrible sufrimiento de la población civil. El 17 de marzo de 1994 después de una negociación que duró toda la noche, logró que se abrieran cuatro rutas de las nueve de la mañana a las dos de la tarde. Los bosnios concordaron en abrir dos de ellas y los serbios otras dos, permitiendo a los civiles en Sarajevo viajar abiertamente al mundo exterior por primera vez desde el estallido de la guerra en 1992.

Las críticas a Sergio durante la operación en Bosnia aumentaron en la medida en que arreciaban los ataques de los serbios a la población civil. La guerra de Bosnia fue el conflicto más violento y prolongado de Europa después de la Segunda Guerra Mundial, con una duración de más de tres años y con un saldo de cerca de 200 mil víctimas entre civiles y militares y 1.8 millones de desplazados, $30 \%$ de las víctimas eran mujeres y niños. Las famosas "áreas seguras" mostraron su enorme vulnerabilidad. Para el diplomático sudamericano, independientemente de la ferocidad de los ataques serbios, UNPROFOR tendría que mantener a toda costa la imparcialidad y no simpatizaba con los bombardeos de la OTAN, supuestamente diseñados para proteger a la población civil, justamente porque ese recurso comprometía la imparcialidad que la ONU necesitaba. Sergio no estaba convencido que los bombardeos de la OTAN se destinarían a la protección de civiles. Tuvieron que ocurrir las masacres de Gorazde y de Srebrenica y las masacres en el mercado de Sarajevo para que los bombardeos a blancos serbios fueran aceptados plenamente por Vieira.

Ciertamente, el concepto de área seguras que él mismo había mantenido mostraron su total inoperancia. Es claro, sin embargo, que no fue Sergio quien creo el concepto. Aquellos que criticaban al brasileño por una imparcialidad que supuestamente le hacia el juego a los serbios, no podían negar que Vieira de Mello defendía el concepto de áreas seguras. Es interesante la reflexión de Michael Barutciski en su artículo: "Safe áreas in Bosnia Herzegovina: some relfections and tentative conclusions" donde destaca que la operación de la ONU en Bosnia Herzegovina fue criticada principalmente por la ineficacia del concepto referido, pero muchas veces sin tener en cuenta en qué contexto surge el concepto, ni cuáles eran las motivaciones reales del mismo.

Claramente el concepto, como señala el autor, brota en un contexto político altamente cargado donde había una gran presión del Consejo de Seguridad para intervenir a favor de una de las partes en el conflicto. Para Barutciski el concepto buscaba tres objetivos principales:

1) Ofrecer protección a la población civil amenazada

2) Aliviar la presión para intervenir más fuerte y directamente a favor de los musulmanes y en contra de los serbios 
3) Apoyar a los musulmanes para atribuir un mínimo de territorio anticipado la inevitable partición de Bosnia Herzegovina.

El autor borda aún más fino al mantener la tesis de que estas áreas se declararon para proteger ciertas poblaciones musulmanas y un partido (aquellas fuerzas leales al presidente Hetbegovic) en un conflicto armado que por lo menos involucraba dos partidos. Cuando Vieira se oponía a la defensa militar de la población civil estaba en plena sintonía con la resoluciones 814 y 819 del Consejo de Seguridad que no comprometía a UNPROFOR a desarrollar un papel militar de defensa activa. Fue hasta la resolución 836 del 4 de junio de 1993 después de la masacre de Srebrenica que se amplió el mandato de UNPROFOR para disuadir los ataques contra las llamadas áreas seguras dando paso a la posibilidad de que UNPROFOR se transformase en una fuerza beligerante, perdiendo su imparcialidad lo que, como siempre señaló Vieira, ponía en riesgo su misión humanitaria, de allí que esa función beligerante fue asumida por la OTAN. Bajo esas condiciones que Sergio acabó, con cierta reticencia, apoyando la intervención de OTAN.

Es decir, parece demasiado simplista la crítica que coloca a Sergio Vieira de Mello como pro serbio. Más bien, como buen funcionario de las Naciones Unidas, se movía hábilmente dentro de los márgenes que le daba el mandato en Bosnia, descrito en las resoluciones del Consejo, estirando la cuerda hasta donde podía. Además, como el propio Kofi Annan argumenta, los limites eran siempre peligrosos dada la ambigüedad de la resolución. Para la implementación de las áreas de seguridad era necesario un mínimo de soldados, pero ninguno de los patrocinadores -como describe en sus memorias, el entonces subsecretario de DPKO-, Reino Unido, Francia, Rusia, España y los Estados Unidos "se ofreció para ampliar su contingente, ni se mostró dispuesto a reubicarlo en las áreas de seguridad recién establecidas." El trabajo de la ONU no era más que el reflejo de las contradicciones del Consejo de Seguridad y Sergio, con toda su habilidad, inteligencia y astucia, no podía ser más que una pieza en ese complejo de interés.

Otra misión que marcó la fulgurante carrera de Vieira de Mello fue cuando Boutros Ghali lo nombró coordinador humanitario de la región de los grandes lagos de África bajo el departamento de asuntos humanitarios (DHA) predecesor de OCHA. Después del terrible genocidio de tutsis por las milicias radicales hutu que habían puesto, una vez más, en entredicho la inoperancia de la comunidad internacional para prevenir la catástrofe humanitaria y el genocidio que se avecinaba en Ruanda, Kofi Annan se refiere a la resolución 872 del Consejo de Seguridad adoptada el 5 de octubre de 1993 del modo siguiente: 
Foi de maior importância-para que se entenda a resolução 872 o clima de aversão a qualquier missão de paz de grandes proporções que imperava no conselho á época, principalmente por parte de Estados Unidos. A decisão sobre a criação de UNAMIR ocorreu poucos dais depois depois do desastre de Mogadiscio. Os Estados Unidos, apoiado por outros países, insistiam agora na rejeição de toda operação de paz que pudesse levar seus soldados ao usa da força e a ter de suportar as complicações e baixas decorrestes disso.

Para garantizar el cumplimiento de los acuerdos de Arusha en los cuales se establecían las condiciones para la formación de un gobierno democrático de coalición se necesitaba, por lo menos, de una fuerza de 5,000 hombres, pero al final fueron enviados solo 2,500. No había disposición alguna para considerar el uso de la fuerza en una misión de paz. El derribo del avión que llevaba a bordo a los presidentes de Ruanda y Burundi fue la gota que derramó el vaso. Como consecuencia de lo anterior se suscita la masacre ante una endeble e inoperante UNAMIR, lo que ocasionó la huida en masa de cientos de miles de refugiados, primero en abril de 1994 a Tanzania y después en julio a la región de los Kivus, Bukavu, Uvira y Goma al este del entonces Zaire. Cuando Sergio asumió como Coordinador Humanitario ocurrió la repatriación masiva de refugiados, en buena medida obligados por los Banyamulengue y las fuerzas rebeldes encabezadas por Kabila, que iniciaba en aquella región de Zaire, una rebelión que iba a durar nueve meses culminando en mayo de 1997 con el derrocamiento del dictador Mobutu apoyado por Francia.

El 14 de noviembre de 1996, los rebeldes kabila en alianza con el gobierno tutsi de Ruanda, apoyado por los belgas, atacaron con artillería pesada desde el oeste el campamento de refugiados de Mugunga, último reducto de los hutus ruandeses que ya albergaba medio millón de refugiados, forzándolos de ese modo a huir hacia el este, es decir, hacia Ruanda; en tanto el escape hacia el Oeste estaba impedido por la propia artillería de los rebeldes. Ese mismo día, el Consejo de Seguridad autorizó el despliegue de una fuerza multinacional de vida efímera porque el mismo consejo ordenó desmantelarla el 23 de diciembre.

Los americanos que habían realizado un monitoreo satelital de los refugiados que lograron huir hacia el oeste e internarse en la selva zariana, criticaron fuertemente al ACNUR porque supuestamente la agencia habría inflado sus números y no había logrado separar a la población civil de los intimidadores. Según cita Samantha Power en su libro sobre Sergio, este enfureció diciendo que los americanos creían que era tan fácil como decirle a la gente "los genocidas a la izquierda y los civiles a la derecha."

Más polémica aún fue la repatriación organizada del lado de Tanzania, bajo la presión del gobierno y a pesar de la fuerte opo- 
sición de Dennis McNamara, entonces director de la división internacional de protección del ACNUR. Sergio Vieira aceptó los argumentos de las autoridades de Tanzania para repatriar a los refugiados según lo firmado el 5 de diciembre de 1996, un comunicado conjunto con el gobierno de ese país, instando a la población a repatriarse a pesar de las enormes preocupaciones relativas a la seguridad de los refugiados. Así y todo, ese comunicado no les informaba que la repatriación debía ser voluntaria, ni tampoco que todo individuo que tuviese temor de persecución en Ruanda, tenía todo el derecho de quedarse en Tanzania. Lo más terrible es que la repatriación no fue ni tranquila ni organizada, sino se realizó a punta de bayonetas y AK-47 empuñados por diez mil soldados. No había duda, se estaba desarrollando, con el consentimiento del ACNUR, una repatriación forzada sin el mínimo respeto por la dignidad humana. Esa fue quizá uno de los momentos más débiles en la brillante carrera de Sergio. Para McNamara, este había tomado el lado del poder. Sin embargo, no estaba solo y contaba con el apoyo de la Alta Comisionada que había cedido a la presión del gobierno de Tanzania y de los Estados Unidos en la necesidad de que el ACNUR colaborara con esa repatriación.

Para Sergio se trataba, una vez más (como lo hiciera en el caso de la repatriación de los camboyanos años atrás), de un decidido pragmatismo en vista de la resuelta actitud de las autoridades de Tanzania por enviar de vuelta a su país a los refugiados ruandeses. Otra vez se enfrentaba el pragmatismo de Sergio contra el principismo de los adalides de la protección. La diferencia es que en el caso de los camboyanos Vieira de Melo esgrimía el muy válido argumento de que había que seguir a la gente, mientras que en el caso de los ruandeses la opinión de los refugiados no parece haber sido tomado muy en cuenta.

Lo paradójico es que por aquel entonces, justo antes de tomar el nuevo cargo que le ofreciera el Secretario General Kofi Annan como Subsecretario para Asuntos Humanitarios en Nueva York, Sergio decía:

La ONU necesita estar más decidida de tomar partido en particular donde hay flagrantes abusos de los derechos humanos: neutralidad, imparcialidad, para parafrasear a Hammarskjold, no significa juzgar a todas las partes de igual manera, equiparando los agresores con las víctimas, pero significa poner en alto los principios establecidos en la carta de las Naciones Unidas, y otros instrumentos internacionales. Esto en algunos casos, puede y debe significar abogar contra una $\mathrm{u}$ otra parte de un conflicto" (Citado por Fabrizio Hochschild).

Sergio, no cabe duda, le imprimió una dinámica diferente a OCHOA que reemplazaba a la antigua DHA a pesar de las inevitables críticas que las agencias operacionales le continuaban ha- 
ciendo a la instancia de coordinación humanitaria de la ONU. Quienes trabajamos cerca de Sergio cuando el jefaturaba ese importante departamento -desde fines de 1997 hasta 1999 en Nueva York- pudimos constatar su enorme liderazgo, sus elevadas cualidades diplomáticas, su actitud respetuosa y afable y su infatigable interés por escuchar a los demás con gran atención y conocimiento. Su presencia elegante y entusiasta, su discurso firme sin bordes de arrogancia, le conferían una gran autoridad no por su jerarquía sin brotes de arrogancia, sino por su carácter e inteligencia pero, sobre todo, por ser portador de una vasta experiencia de terreno. Por eso siempre le decía al personal joven: "Estén en el terreno, eso es.

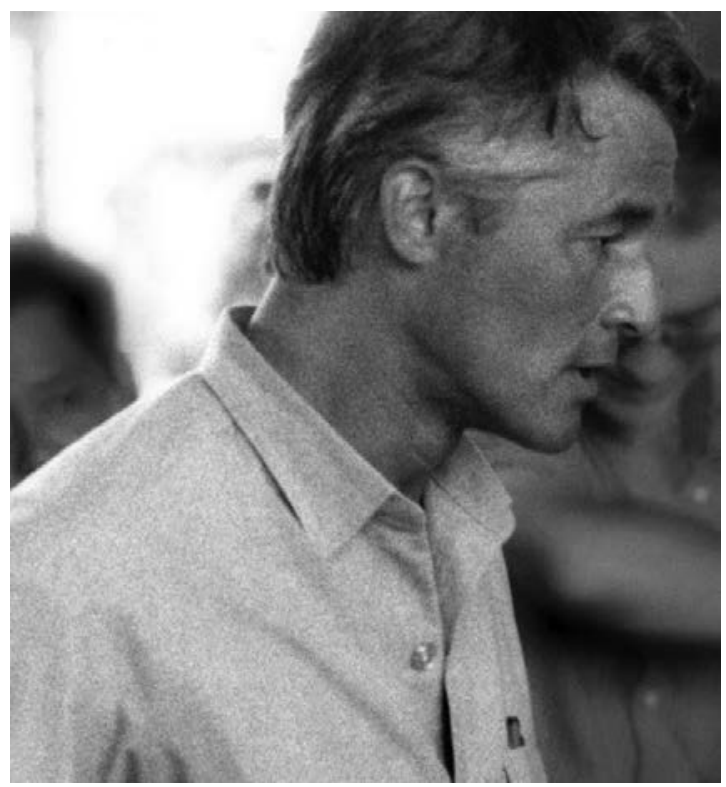

Es así que construí mi carrera. Eso es lo que es relevante, nada más importa" (Citado por Samantha Power).

De hecho, esa sed permanente por no perder el contacto con el terreno pronto lo llevó a salir de sede. Parecía que para él estar en la sede era como la necesidad del pez de subir a la superficie a tomar un poco de oxígeno, pero tras unos instantes necesita penetrar de nueva cuenta a las profundidades del mar que para él equivalía al terreno, el lugar donde se sentía en su hábitat natural.

Esta vez fue nombrado por el Secretario General su representante especial en Kosovo. En octubre de 1998 el Consejo de Seguridad había aprobado una resolución en la que demandaba a los serbios cesar sus ataques a la etnia albanesa en Kosovo. Para ello, autorizó el envío de monitores internacionales y le pidió al Secretario General enviar una misión de las Naciones Unidas a Kosovo para verificar que las tropas serbias efectivamente se habían batido en retirada regresando a sus cuarteles. Se estaban desplegando a lo largo y ancho de la pequeña provincia de apenas diez kilómetros cuadrados, monitores civiles y desarmados de la OsCE.

Quienes participamos de esa misión en que recorrimos toda la provincia en un día, incluidas reuniones con los jefes de las oficinas del ACNUR aún en construcción y aún carentes del personal necesario en los principales poblados del país, nos percatamos que todo era una farsa, que el repliegue de las tropas serbias era una mera simulación y que en cualquier momento 
podían salir de nuevo y atacar con toda su furia a los albaneses. Sabíamos que el acuerdo por montar esos monitores desarmados había sido resultado de un pacto secreto entre Milosevic y Hoolbroke, viejos conocidos de los acuerdos de Dayton de 1995. Aunque nadie sabía exactamente en qué había consistido el pacto, nadie era optimista al respecto. Se sabía que Kosovo era la niña de los ojos de Milosevic desde su vehemente discurso en defensa de los sagrados derechos de los serbios en abril de 1987. Dice el historiador Noel Malcolm en su breve historia sobre este territorio: "Desde ese día, su naturaleza como político cambio: fue como si una droga nueva y poderosa hubiera penetrado en sus venas" (traducción propia). Desde entonces Milosevic explotó el asunto de Kosovo y se transformó en un líder nacional, era muy difícil que abandonase la herramienta que tantos dividendos políticos le había dado.

En febrero de 1999 diplomáticos de los Estados Unidos, Europa y Rusia convocaron a las partes a desarrollar negociaciones en Rambouillet, Francia, partiendo de la base de un plan según el cual Kosovo se mantendría como provincia de Serbia, pero con niveles sin precedentes de autoestima. Había escepticismo de todo el mundo, al punto que mientras se desarrollaban las conversaciones con el acuerdo de los albaneses de Kosovo, los serbios se retiraron de la mesa al tiempo que 40,000 tropas serbias se lanzaban en poderosa ofensiva. Hoolbroke advirtió a Milosveic que, si no aceptaba el acuerdo de Ramboullet, la OTAN comenzaría a bombardear Serbia. La guerra estaba declarada, a pesar de que Javier Solana, Secretario General de la OTAN, hiciera una gran propaganda alegando que se trataba de una intervención humanitaria y se apresurara a colocar sus banderas para los reflectores de televisión en las zonas de recepción de miles refugiados, sobre todo en Albania. La respuesta de ACNUR fue lenta ante la furiosa embestida serbia que forzaba la salida intempestiva y masiva de familias enteras. Mientras tanto, la OTAN alanzaba su lluvia de bombas sobre Belgrado causando múltiples víctimas civiles como resultado de los eufemísticamente llamados daños colaterales.

Los serbios, sin embargo, no se rendían. Los rusos lograron presionar para lograr el cese al fuego, proponiendo que la Naciones Unidas, más que la OTAN, jugaran un rol dominante en la transición post-Bélgica. Sergio encontró la fórmula para posicionar a la ONU al hacerse cargo del aspecto humanitario de la transición posguerra y liderando un equipo internacional dentro de Kosovo para desarrollar una misión de evaluación e informar de primera mano al Consejo de Seguridad.

Finalmente, después de 12,500 bombardeos y ya teniendo claro que la OTAN y la ONU habían logrado construir finalmente en frente unido, Milosevic se rindió. El corolario natural fue la resolución del Consejo de Seguridad 1244 que le pedía al se- 
cretario general nombrar un representante especial en Kosovo como administrador tradicional.

Esta persona se haría cargo de la administración civil vía la unión europea, de los aspectos humanitarios vía el ACNUR, de la reconstrucción a través de la unión Europea y de la construcción institucional por medio de la OSCE. El administrador debería trabajar conjuntamente con la OTAN que desplegaría 50 mil tropas en un rol de mantenedores de paz. No fue sorpresa para nadie cuando Sergio fue nombrado. Todo parecía moverse vertiginosamente; a mediados de junio, Sergio ya estaba en el terreno con su equipo esencial montado y en espera de las oleadas de la repatriación masiva. Para el 25 de junio ya se habían repatriado más de 650 mil refugiados. El trabajo para Sergio era vasto, en tanto bajo su mando estaría la supervisión general de todos modos la OTAN. Sergio estuvo apenas allí un mes. Su tarea más importante en ese corto período fue el establecimiento del consejo de transición compuesto de representantes de todos los grupos étnicos.

La formación del consejo no fue fácil, ante las expectativas del ejército de liberación de Kosovo (ELK) por gobernar la provincia, en tanto se consideraba asimismo como la principal fuerza que había luchado por la independencia y tenía los recursos y el personal suficiente para ser desplegado a lo largo de la provincia, mientras que en frontal oposición, Ibrahim Rugova fundador del movimiento pacifista de Kosovo al regresar del exilio, se sentía con la autoridad y merito suficiente como para erigirse en el legítimo presidente de la provincia. Para Sergio, la cosa era clara: nadie podría proclamarse presidente hasta que no se llevaran a cabo elecciones libres. Al parecer, a pesar de las frustraciones derivadas de la lucha intestina entre los propios kosovares albaneses, según narra Samantha Power, lo que más le dolió a Vieira de Mello fue el enterarse que no sería el administrador permanente de Kosovo. Los europeos habían decidido financiar la reconstrucción con 1.5 billones de dólares y, como era de esperarse, querían a un europeo al frente de la providencia. El 2 de julio, Kofi Annan anuncio el nombramiento de Bernard Kouchner ex ministro de salud de Francia y fundador de médicos sin frontera y, unos pocos días después, el 15 de julio, este era recibido por Sergio en el aeropuerto de Pristina como nuevo representante especial del Secretario General.

El incansable carioca, ni quería quedarse quieto ni lo dejaban tranquilo en el piso 36 del secretario de las Naciones Unidas en Manhattan donde se ubicaban sus oficinas de Subsecretario de Asuntos Humanitarios. No habían pasado ni 4 meses de su retorno de los Balcanes cuando el 8 de noviembre empacaba sus maletas de nueva cuenta, ahora para dirigirse hacia Timor del Este como gobernador. La resolución 1272 del Consejo de Seguridad mandataba a las Naciones Unidas para hacerse cargo de un gobierno transición y decidió establecer UNTAET. El pueblo de Timor del Este acababa de ganar el referéndum con casi el 
$80 \%$ de votos a favor de la independencia de la parte oriental de la isla. Sin embargo, milicias apoyadas por el ejército y la policía de Indonesia reaccionaron violentamente masacrando a cientos de timorenses. Ante tales acontecimientos, el consejo de seguridad envío una fuerza multinacional (INTERFET) de 11,500 hombres bajo el comando de Australia a fin de detener la masacre. Derrotados los indonesios también en el plano militar, la pequeña isla estaba devastada y necesitaba de ayudar exterior de manera que, aunque el líder de la resistencia Xanana Gusmao, héroe nacional, poeta y revolucionario que había estado encarcelado por los indonesios desde 1993, estaba llamado a ser el presidente de la nueva nación independiente, tuvo que aceptar resignado la resolución 1272 . Esta parecía una calca de la resolución 1244 para Kosovo y no había duda que el hombre ideal para llevarla a cabo era nuevamente Sergio. Sin dejar su cargo en OCHOA, Vieira de Mello pensaba que solo trabajaría seis meses al frente de UNAMET. No obstante, acabó por ocupar el cargo dos años y medio; nunca antes ni después, un Subsecretario de las Naciones Unidas para asuntos humanitarios iba a ejercer mucho más tiempo en el terreno que en la sede.

El reto principal para el experimentado diplomático sudamericano era llevar a la práctica con éxito el plan para compartir el poder con los timorenses al tiempo que les garantizaba seguridad económica y física en el día a día. La fina habilidad en la que nuestro personaje se concentraba cotidianamente consistía en respetar la autoridad de Gusmao sin reconocerla en lo formal, por lo que se ganó la simpatía de la gente, aprendiendo el tetum, la lengua local, que en parte se le facilitaba por tener esta varias palabras prestadas del portugués. Como señalo el por muchos años Canciller de Timor del Este en el exilio, Ramos Horta, Vieira se ganó confianza y simpatía de todos los líderes comunitarios, de la iglesia y en general de todos los sectores. Sergio estaba muy consciente del sufrimiento del pueblo timorés, sumido en la pobreza y la parecía una barbaridad que mientras el presupuesto de UNAMET era de 692 millones de dólares, el presupuesto para toda Timor del Este no alcanzaba para cuestiones básicas: “Tengo la autoridad de ordenar a las tropas que abran fuego sobre los líderes de las milicias pero no tengo autoridad para darle una computadora a Xanana Gusmao".

Sergio sabía que había que acelerar el proceso, Gusmao y su partido así lo percibieron. Hoy, a diez años de su muerte, así lo reconoce el ex Presidente de Timor del Este y premio nobel de la paz, Ramos Horta, cuando en reciente evento en homenaje a Vieira de Mello, organizado por Itamaraty y las Naciones Unidas de Rio de Janeiro, explicaba que solo una figura como Sergio podía tener la fuerza necesaria para lograr el reclutamiento de la operación de paz con la agilidad necesaria. Sin embargo, la tarea no se realizaba en un lecho de rosas. Gusmao reclamaba que no había un cronograma claro, hacía ver que el pueblo timorés 
se preguntaba con razón, ¿cuándo se retirarían los extranjeros de Timor del Este? Sergio le puso fecha al proceso que conduciría al anhelado día en que la independencia de Timor se haría efectiva.

En agosto de 2001 se eligió una asamblea constituyente formada por 80 miembros, la misma elaboraría y adoptaría una constitución en 90 días y decidiría la fecha de la elección presidencial. Para mediados de septiembre Vieira había formado un nuevo gabinete compuesto solamente por timoreses. Como dijera recientemente Sadako Ogata, Alta Comisionada para Refugiados de1991 al 2001: "siempre lo identifique con un trabajador de campo" "El siempre buscaba soluciones". Kofi Annan lo sabía bien y se sintió muy orgulloso de lo alcanzado por la ONU en Timor del Este:

Tinhamos honrado a palabra dada ao povo do Timor Leste; nos momentos de maior peligro, ficamos ao seu lado por meio de uma campanha diplomática que obtuve a anuencia da Indonesia e o apoio da comunidade internacional; interrompemos a massacre, os saques e os incendios; e levamos ao país, etão a beira do colapso, para o caminho da aotodeterminação. $\mathrm{O}$ preço disso, para o povo timorense, foi altíssimo. Mas num mundo em que poças vezes são atendidas as justas demandas de uma população que exige segurança e autodeterminação, tínhamos conquistado uma rara victoria.

El 21 de mayo de 2002, Sergio, satisfecho del importante logro alcanzado, dejaba las tierras timorenses y apenas dos meses después, Kofi Annan le ofreció el cargo de Alto Comisionado para los Derechos Humanos. Ya había sido un fuerte candidato para suceder a Sadako Ogata como Alto Comisionado para Refugiados el año anterior, pero el puesto se lo habían dado a Rud Lebbers, ex Primer Ministro de Holanda y ahora tendría el gran desafío de ponerse al frente de una organización en la que difícilmente podría mantener su característica simpatía con todas las partes. Él mismo no se sentía el típico defensor de los Derechos Humanos, aunque era claro que toda su vida, en su propio estilo, había sido de hecho un gran defensor de los derechos de las personas.

La oficina del Alto Comisionado tenía un presupuesto bastante bajo de apenas 66 millones de dólares de aquel entonces. Sergio percibió desde su llegada a la oficina en Ginebra que la gran mayoría de los funcionarios habían trabajado siempre en la sede y no habían pisado el terreno, de modo que para él era vital desarrollar un sistema de rotación al terreno para que el personal se empapara de la realidad de la violación de los derechos humanos en donde realmente acontecían las violaciones a estos y no meramente a nivel teórico desde la herrumbre burocrática de sus escritorios en la sede. Sin embargo, habría de ser 
él mismo quien, como siempre a lo largo de su carrera, no iba a durar demasiado tiempo en tierras ginebrinas. Esta vez, sin embargo, por extraño que parezca dejó la sede muy a su pesar.

Estallada la guerra liderada por los americanos contra Irak el 20 de marzo del 2003, en marcadas condiciones de ilegalidad y de ilegitimidad, llevada a cabo a espaldas del Consejo de Seguridad de las Naciones Unidas, se había suscitado un claro repudio internacional. Sin embargo, meses más tarde, el 22 de mayo, los Estados Unidos conscientes de la necesidad de legitimar el ataque, así fuese a posteriori con el copatrocinio de sus aliados británicos y españoles, consiguieron convencer a los otros miembros del Consejo de Seguridad General nombrar a un representante especial para Irak. A pesar de las duras críticas que esa resolución generó al interior de la Naciones Unidas, lo cierto es que para Kofi Annan la resolución era importante.

O que determinei nos dias posteriores a invasao, depois de muito pensar, foi que tinhamos um dever para com o povo do Iraque que ia além dos sentimentos de traição ou desaprovação que qualquer um de nos pudesse experimentar os Iraquianos precisavam de nossa ajuda e, como Naçoes Unidas tínhamos a obrigação a presta-la Não seria realista nem dejajável que nos esquivássemos do cumprimento de nosso papel numa arena pos-conflito tão graves consequências.

En cumplimiento a la resolución 1483, el Secretario General le pidió a Sergio, nuevamente, ser su representante especial. Nuestro personaje había decidido, por primera vez en su larga carrera de más de treinta años con las Naciones Unidas, pensar en su vida personal y le costó mucho trabajo aceptar la tremenda responsabilidad. Además, era consciente de la enorme responsabilidad que recien- 
temente había adquirido como Alto Comisionado de Derechos Humanos por lo que aceptó el ofrecimiento bajo el entendido de que su misión en Irak se extendería por un máximo de cuatro meses. El 3 de junio llegó a Bagdad y dedicó sus primeras semanas a viajar intensamente por el complejo país ocupado y a dialogar con los diversos sectores y grupos étnicos de la compleja sociedad iraquí de tradiciones ancestrales. Quería entender sus problemas, sus sentimientos y aspiraciones antes de darse a la complicada tarea práctica de avanzar en la construcción de instituciones y de una administración interna entre las múltiples tareas relacionadas con aspectos humanitarios, de derechos humanos y reconstrucción que la resolución exigía. Todo ello en coordinación con las fuerzas ocupantes en condiciones sumamente complicadas en tanto debía mostrarse independiente de la misma, e inclusive distante, habida cuenta de la creciente ola de resistencia del pueblo iraquí contra la ocupación.

Vieira de Mello era muy consciente que su rol en Irak era mucho más complicado que en Bosnia-Herzegovina donde UNPROFOR, a pesar de sus debilidades y pasividad, jugaba claramente un rol humanitario y no era propiamente visto como un enemigo de ninguno de los bandos en conflicto. Lo mismo no era comparable con UNMIK en Kosovo a pesar de las enormes desconfianzas y complejidades interétnicas, no se veía a los ojos de la mayoría kosovar como una fuerza multinacional de la OTAN, allí jugaba más bien un rol de mantenimiento de paz. Ni tampoco se podía equiparar con UNMET en donde claramente las Naciones Unidas habían colaborado de manera incuestionable en hacer efectiva la voluntad popular de la independencia timorense y ayudaron a la transición política administrativa de un país recién nacido. En Irak, por más que Vieira de Mello se esforzase por deslindarse de los ocupantes, era claro que la misma resolución 1483 lo obligaba trabajar conjuntamente con ellos y eso era bien sabido por la resistencia y por grupos terroristas activos en el país. 
Con el dinamismo y determinación que lo caracterizaba, Vieira de Mello se dio a la tarea de formar junto con Bremer, Director de la reconstrucción y asistencia humanitaria de la coalición ocupante, un consejo gobernante, tratando de darle la máxima representatividad y responsabilidad posibles haciendo énfasis en garantizar una significativa membresía suní. De todos modos, para la resistencia ese consejo era una marioneta de los ocupantes y, por otra parte, Sergio tenía que vivir la frustración de que en términos prácticos la ONU era un jugador menor delante de los ocupantes que eran quienes realmente mandaban. No es casual que poco antes del atentado en el hotel canal de Bagdad donde operaban las Naciones Unidas, Sergio se empezaba a sentir vulnerable. Estaba convencido que por mucho que se hubiese adoptado la resolución que legitimaba formalmente la ocupación, esta jamás iba a ser legitima. Escribió un par de días antes del atentado:

En el poco tiempo que he estado en Irak he sido testigo de la realidad de la ocupación. He llegado a cuestionar si ese estado de cosas puede alguna vez ser verdaderamente legítimo. Ciertamente, la ocupación puede ser apoyada legalmente. La ocupación puede ser llevada a cabo benignamente, basada en nada que no sea buenas intenciones. Pero moralmente y prácticamente, dudo sin algún día va a ser legítima: su tiempo si alguna vez lo tuvo, ha pasado. (Traducción propia del original citado por Samantha Power).

El 19 de agosto de 2003, es decir apenas dos meses y medio después de la llegada de Vieira de Mello a Irak, un atentado de un camión bomba que había entrado con facilidad hasta el lugar justo debajo de la oficina de Sergio acabó con la vida de 22 funcionarios de la ONU, entre ellos la de Vieira de Mello. Aún agonizante preguntaba por sus colegas, así terminó su misión con las Naciones Unidas, pendiente de su equipo hasta que su gran corazón cesó de latir.

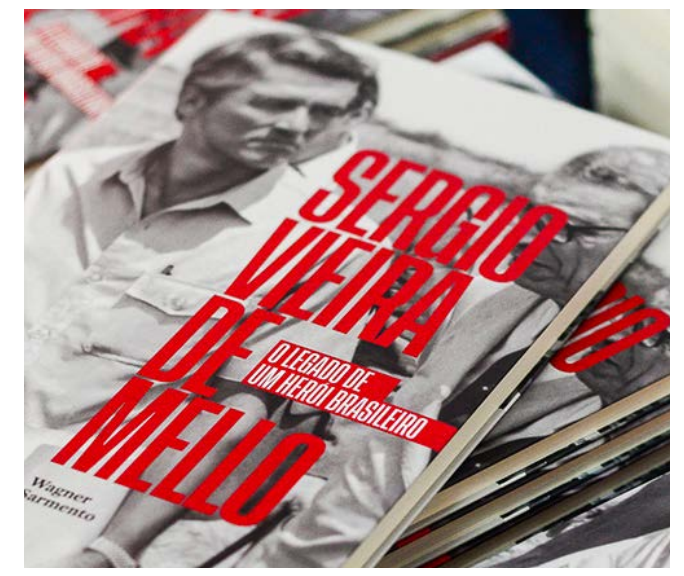

